\title{
Oral Effects of Renal Disease: A Medical Problem in Dentistry
}

\author{
SZ Mahmud", MM Uddin², SZ Eusufzai ${ }^{3}$, NA Nomann ${ }^{4}$, SM Hossain ${ }^{5}$, MA Tarafder ${ }^{6}$
}

\begin{abstract}
The number of patients with chronic kidney disease especially with diabetic nephropathy is expected to grow significantly in the future. It is associated with substantial morbidity and mortality, and the consequence of this emerging public health problem is considerable consumption of medical and financial resources. Thereby, there is a higher chance to see such patients in a dental office. People with kidney disease and those on dialysis are more likely to have periodontal disease and other oral health problems than the general population. Build up of bacteria in the mouth can cause infection. Because people with kidney disease have weakened immune systems, they are more susceptible to infections. Moreover, bone loss in the jaw can occur in those with kidney disease. Calcium imbalance contributes to loss of calcium from the bones resulting in weak bones. Weak bones can cause teeth to become loose and potentially fall out. The doctor may recommend antibiotics be taken prior to the dental procedure to help guard against infection. The purpose of this article is to evaluate oral and dental manifestations in patients on haemodialysis and kidney transplant recipients, and understanding the use and adjustment of common dental drugs which aid clinicians in safely treating these patients as well as to clarify the possible basic role in managing renal disease patients.
\end{abstract}

Key words: Kidney disease, dental drugs, oral manifestation, renal nutrition, transplantation.

\section{Introduction}

Chronic kidney disease is defined by the presence of a marker of kidney damage, such as proteinuria (ratio of greater than $30 \mathrm{mg}$ of albumin to $1 \mathrm{~g}$ of creatinine on

1. Dr. Shaikh Zakir Mahmud BDS, MPH, Medical Officer (Dental Surgeon),, National Healthcare Network (NHN) Mirpur Centre, Dhaka, Bangladesh

2. Dr. (Lt. Col.) Mohammad Mesbah Uddin BDS, Consultant, Saba Dental Care, DOHS, Baridhara, Dhaka, Bangladesh.

3. Dr. Sumaiya Zabin Eusufzai BDS, MPH, Senior Lecturer, Department of Public Health, Northern University Bangladesh, Dhaka, Bangladesh.

4. Dr. Nahid Al Nomann BDS, Doctoral Fellow, Division of Clinical Cariology and Endodontology, Department of Oral Rehabilitation, School of Dentistry, Health Sciences University of Hokkaido, Japan.

5. Dr. (Lt. Col.) Sarder Mahmud Hossain MBBS, DHM, $\mathrm{PhD}$, Professor \& Head, Department of Public Health, Northern University Bangladesh, Dhaka, Bangladesh.

6. Dr. Monowar Ahmad Tarafder MBBS, DIH, MPhil, $\mathrm{PhD}$, Professor \& Head, Department of Community Medicine, Zalalabad Ragib Rabeya Medical College, Sylhet, Bangladesh.

\section{Address of Correspondence:}

Dr. Shaikh Zakir Mahmud BDS, MPH, Medical Officer (Dental), NHN Mirpur Centre, An Enterprise of the Diabetic Association of Bangladesh, Commercial Plot No. 27-28, Block-Kha, Main Road-1, Section-6, Mirpur Dhaka-1216, Bangladesh.

E-mail: suman79_bd@yahoo.com untimed [spot] urine testing), or a decreased glomerular filtration rate (GFR $<60 \mathrm{~mL}$ per minute per $1.73 \mathrm{~m}^{2}$ ) for three or more months. ${ }^{1}$ Estimates of the global burden of disease indicate that diseases of the kidney and urinary tract account for approximately 830,000 deaths and 18,467,000 disability-adjusted life years annually, ranking them 12th among causes of death (1.4 percent of all deaths) and 17th among causes of disability (1.0 percent of all disability-adjusted life years). ${ }^{2}$ In the United States, kidney failure is becoming increasingly common and is associated with poor health outcomes and high medical expenditures. In 2009, 116,395 patients started therapy for end-stage renal disease (ESRD), and the prevalent population reached 571,414 (including 398,861 dialysis patients); 17,736 transplants were performed, and 172,553 patients had a functioning graft at year's end. ${ }^{3}$

There is about $5 \%$ annual increase in the number of patients with chronic kidney failure, patients undergoing haemodialysis or kidney transplantation. ${ }^{4}$ Around 20 million (two crore) people have been suffering from kidney diseases, especially chronic kidney disease (CKD) in Bangladesh. Kidney diseases claim at least five lives every hour and over 40,000 lives a year. Nearly 85 percent of the patients do not realize they are affected by kidney diseases before going for treatment. ${ }^{5}$ Although national registries are not available, the data from different medical colleges and community based studies in this country suggest that glomerulonephritis, acute and chronic renal failure, urinary tract infection, renal stone diseases and obstructive uropathy are common renal problems. ${ }^{6}$ 
Improper kidney function is reflected in every organ system of body, showing various signs and symptoms. About $90 \%$ of renal failure patients have oral symptoms. ${ }^{7}$ Diabetes mellitus is the most frequent cause of ESRD. Type 2 diabetes mellitus accounts for about two thirds of diabetes-related cases. Hypertension is the second most frequent cause of ESRD. Renal arterial diseases-including both large and small vessel disease-appear to be raising incidence, especially in the elder. The causes of chronic renal failure (CRF) are similar to those for ESRD. ${ }^{8}$ Renal disease has become important in dentistry because of the growing number of patients who, as a result of renal dialysis or transplantation, survive renal failure. Aspects of renal disease affecting dental management are: Heparinisation before dialysis, Possible hepatitis B or $\mathrm{C}$ carriage after chronic dialysis, Permanent venous fistulae susceptible to infection, Secondary hyperparathyroidisam, Immunosuppressive treatment for nephritic syndrome or transplant patients, Oral lesions due to drugs, particularly for immunosuppression, Low doses or withholding of many drugs: e.g. some cephalosporins and tetracyclines, and Oral lesions of chronic renal failure. ${ }^{9}$

A new study has revealed that patients suffering from end-stage renal failure (ESRF) and those receiving dialysis are more prone to periodontal disease and other oral health problems. The renal failure groups had higher gingival index (GI) and bleeding, probing depths, attachment loss, hypoplasia and obliteration and less caries, than the control. Plaque was higher in the dialysis and pre-dialysis (PD) groups. Dialysis duration and end-stage renal failure significantly correlated with gingivitis, probing depth, attachment loss and enamel hypoplasia. ${ }^{10}$ Several studies have demonstrated higher rates of oral pathology in dialysis patients with one or more oral symptoms such as xerostomia, taste disturbances, uremic odor, tongue coating, mucosal inflammation, mucosal petechia/ecchymosis, oral ulceration, or enamel hypoplasia. Xerostomia (or dryness of the mouth) may predispose to caries and gingival inflammation as well as contribute to difficulties with speech, denture retention, mastication, dysphagia, sore mouth, loss of taste, and infections. ${ }^{11}$

\section{Oral and dental manifestation}

Xerostomia: The main oral health problem experienced by renal patients is xerostomia.
This is as a result of several factors which include multiple medication, restricted intake of fluids and diabetes in which many renal patients suffer from. Xerostomia may also predispose the patient to caries, mucositis and oral infection as the protective factors in saliva are not present. For the HD and immunosuppressed transplant patient infections in the oral cavity may act as foci in other sites of the body. ${ }^{12}$

Bad odor (secondary to uremia) and metallic taste: People with renal problems may have a bad taste and odor in their mouths, which occurs because the kidneys are not removing urea from the blood resulting from the increased concentration of urea in saliva and the urea is breaking down to form ammonia. ${ }^{13}$

Plaque and calculus: Dialysis patients may form calculus more rapidly than healthy individuals possibly due to high salivary urea and phosphate levels. ${ }^{14} \mathrm{~A}$ significant correlation between plaque scores and gingival inflammation in renal dialysis patients has also been reported. ${ }^{15,16}$

Stomatitis: In kidney failure, blood urea level increases which results in uremic stomatitis. Uremic stomatitis in the following two forms: Erythemopultaceous form characterized by red mucosa covered with thick exudates and pseudomembrane and Ulcerative form characterized by ulcerations with redness and pultaceous (pulpy) coating. ${ }^{17}$

Gingival hyperplasia: One of the most typical findings in patients with endstage renal failure is gingival hyperplasia (drugi indused gingival overgrowth), which mechanism of occurrence is multifactorial and still unknown. Taking antihypertensive drugs (calcium channel blocker) and immunosuppressive drugs give its impact in the oral cavity. Such gingival expansion occurred more frequently in the early post-transplant period (4 months) and in combination with low oral hygiene. ${ }^{18}$

Hairy leukoplakia: Oral hairy leukoplakia $(\mathrm{OHL})$ is associated to the Epstein-Barr virus (EBV), and different studies suggest that primary infection occurs in the oropharynx, where the virus remains latent in the basal layers of the epithelium until reactivation takes place as a result of immune depression - with the generation of tongue lesions. ${ }^{19}$

Enamel hypoplasia: Children with renal failure may have enamel hypoplasia and dysplastic dentine with delayed eruption of teeth. ${ }^{9}$ 
Jaw bone alteration: Other oral manifestations of renal disease are related to renal osteodystrophy (RO), a common condition which is considered as a dysfunctional mineral homeostasis. These manifestations appear in late stage. Disorders in calcium and phosphorus metabolism, abnormal vitamin D metabolism and increased compensatory parathyroid activity are the main causes. Secondary hyperparathyroidism develops when the kidney secretes more phosphate ions and also osteoblastic and osteoclastic activity increases. Cortical expansion and gingival swelling originated from giant cell lesions may occur. $^{20}$ The oral manifestations of hyperparathyroidism appears frequently in the mandibular molar region these changes are: Total or partial loss of lamina dura, Bone demineralization, Loss of trabeculation, Giant cell tumors, Tooth mobility, Malocclusion, Metastatic soft tissue calcifications, and The teeth may be painful on percussion and mastication. Malocclusion is due to increased mobility and drifting of teeth and demineralization of temporomandibular and paratemporomandibular bones. ${ }^{17}$

Erosions: Severe erosions on the lingual surfaces of the teeth, due to frequent regurgitation and vomiting induced by uremia and medication, and nausea associated to dialysis. ${ }^{21}$

Malignization: Normal renal function and health can be restored by transplantation, but it is associated with the complications of prolonged immunosuppressive treatment, particularly susceptibility to infections or lymphomas. ${ }^{9}$

\section{Oral and dental management}

End stage renal failure is a life threatening condition. The kidneys regulate fluids, excrete nitrogenous waste, synthesize vitamin D and erythropoietin (EPO), maintain acid-base homeostasis regulate mineral and electrolyte balance and regulate the metabolism and excretion of drugs. All of these things can affect dental treatment due to the resulting abnormalities. Dialysis patients are heparinized and so in order to avoid abnormal bleeding tendencies, treatment should be carried out the day after dialysis. The patient has the maximum benefit from the dialysis and the effect of the heparin has worn off. For the transplant patient only emergency treatment should be carried out within the first three months after transplantation. It is also suggested that transplant recipients should receive antibiotic prophylaxis prior to dental treatment. ${ }^{22}$

\section{Dental drugs}

Drugs that are directly nephrotoxic must be avoided. Drugs excreted mainly by the kidney may have undesirably enhanced or prolonged activity if doses are not lowered. Drug therapy may need to be adjusted, depending on the degree of renal failure, the patient's dialysis schedule, or the presence of a transplant. Except in emergency, such drugs should be prescribed only after consultation with the renal physician. ${ }^{23}$

Antibiotics: Renal disease also has significant effect on antimicrobials. Because dosage adjust is required for most antimicrobials, it is of practical value for the clinicians to be familiar with the oral antibiotics that do not need dosage reductions. Penicillins not requiring dosage adjustment in case of moderate renal insufficiency include dicloxacillin, nafcillin and penicillin VK. Penicillins have a wide therapeutic margin of safety but are neurotoxic at high dosages and seizures can occur. Of the oral cephalosporins, only cefuroxime axetil needs no dosage adjustment. Macrolides not requiring adjustment include erythromycin and azithromycin. Doxycycline and minocycline are excreted via the biliary route, do not accumulate, do not aggravate uremia and, thus, do not need dosage adjustment. Clindamycin is the other commonly used dental oral antibiotic not needing dosage adjustment. Once a patient's Glomerular filtration rate (GFR) declines to less than 50 $\mathrm{mL} /$ minute, most other antibiotics require dosage or dosing interval adjustment. ${ }^{24}$

Fluorides: Fluoride can usually safely be given tropically for caries prophylaxis. Systemic fluorides should not be given, because of doubt about fluoride excretion by damaged kidneys. ${ }^{23}$ For patients receiving haemodialysis (HD) and continuous ambulatory peritoneal dialysis (CAPD), serum fluoride accumulation is a risk factor. ${ }^{25}$ Persistent high levels of plasma fluoride in such patients can cause osteodystrophy and other done damage. ${ }^{26}$ If fluoridated community water is used to mix the dialysates, it may lead to fluoride toxicity, fluorosis and renal osteodystrophy. So dialysis patient should receive dialysates that are mixed with purified and de-ionized water. ${ }^{17}$

Immunosuppressives: In general, kidney transplants involve the risk of transplanted organ rejection. In order to prevent this, patients who have undergone an organ transplant operation, are given huge doses of immunosuppressants such as corticosteroids, azatioprin, 
cyclosporine and anti-lymphocyte globulin. Accordingly, in patients who underwent kidney transplant operations prophylactic antibiotics should be administered in consultation with the patient's physician. Because of potential adrenalin crisis risk, it is necessary to alter steroid therapy. If the stress suffered during the oral surgical intervention is minimal, the therapy should be altered. If the stress in insignificant, it is recommended to increase the steroid dosage twice a day two days prior and following the oral surgical intervention. If the stress is great, $100 \mathrm{~g}$ of hydrocortisone should be administered i.m. prior to the operation, gradually reducing dosage by $50 \%$ on a daily basis for three days after the intervention until the dosage of $20 \mathrm{mg}$ which should be administered twice a day for the subsequent 7 days. In any case, steroid dosage is administered by the expert physician after consultations with the dentist and the expert stress assessment. $^{27}$

Analgesic: aspirin and other non-steroidal antiinflammatory drugs (NSAIDS) should be avoided science they aggravate gastrointestinal irritation and bleeding associated with chronic renal failure (CRF). Their excretion may also be delayed and they may be nephrotoxic, especially in the elderly or where there is renal damage or cardiac failure. Some patients have peptic ulceration, which is a further contraindication to asprin. Even COX-2 inhibitors may be nephrotoxic and are best avoided. ${ }^{23}$ For mild pain, acetaminophen is the analgesic of choice and is safe in chronic kidney disease (CKD). It is extensively metabolized by the liver with less than $5 \%$ excreted unchanged via kidney. For moderated pain, and pain inadequately controlled acetaminophen, weak opioids should be considered. For patients with severe pain or on-going moderate pain despite weak opioids, strong opioids are recommended. Those believed most efficacious and safe in CKD patients are hydromorphone, methadone, and fentanyl. ${ }^{28}$ Tapentadol has recently been introduced into clinical and has been approved by the FDA for moderate to severe pain, and the potency is said to be somewhere between morphine and tramadol. It does not appear to cause the confusional states sometimes associated with tramadol. In various studies, tapentadol has been found to be effective even for severe postoperative pain. ${ }^{6}$ There is every possibility that tapentadol may improve upon the analgesic safety of morphine and tramadol while reducing the incidence of side-effects, if used appropriately. ${ }^{29}$
Local Anaesthesia and conscious sedation: Local anaesthesia is safe unless there is a severe bleeding tendency. Relative analgesia (conscious sedation) may be used. The veins of the forearms and the saphenous veins are lifelines for patients on regular haemodialysis. If it is necessary to give intravenous sedation, or take blood, other veins such as those at or above the elbow should be used because of the risk of consequent fistula infection or thrombophlebitis. Midazolam is preferable to diazepam because of the lower risk of thrombophlebitis. ${ }^{23}$

General anaesthetics: Patients with chronic renal disease (CRD) have multiple general anaesthesia (GA) risk factors. ${ }^{30}$ General anaesthetics pose specific problems for renal patients as they are highly sensitive to the myocardial depressant effects. Myocardial depression and dysrhythmias are especially likely in poorly controlled metabolic acidosis. ${ }^{23}$ Chronic anaemia is common in patients with CRF who are not being treated with erythropoeitin and is usually well tolerated. Unless the patient has ischaemic heart disease the haemoglobin level may be maintained at around $7-8 \mathrm{~g} / \mathrm{dl}$. Uraemic patients may have a bleeding tendency due to a decrease in platelet adhesion and fragility of the vessel walls. ${ }^{31}$ However there is no evidence that GA presents a higher risk than other techniques. In general, there is a lack of research comparing outcomes from different anaesthetic methods. In one retrospective study there was no increase in mortality, cardiac morbidity or fistula failure in patients undergoing procedures under general anaesthesia compared to local anaesthsia (LA) infiltration or regional anaesthesia (RA) brachial plexus block, although the comparison was underpowered. Patients often have an expectation of general anaesthesia when presenting for surgery. With careful planning they can be offered GA with minimal increased risk. ${ }^{30}$

Anti-fungal: For mucocutaneous candida infection, topical therapy with clotrimazole or nystatin is usually effective, but if this fails fluconazole therapy is suggested. In general, mucocutaneous overgrowth can be prevented by treatment of high-risk patients (those receiving antibiotic therapy, or high-dose immunosuppression) with nystatin oral washes. For life-threatening infection, Amphotericin B is probably more effective because it controls the infection sooner, although fluconazole is less toxic. 
Fluconazole increases cyclosporine levels and therefore cyclosporine levels must be frequently checked when patient is on fluconazole. Liposome Amphotericin has been used instead of Amphotericin B because there is less nephrotoxicity with similar efficacy; however, it is very expensive. ${ }^{32}$

Adjuvant and other drugs: Adjuvant drugs refer to medications with a primary indication other than pain that possess analgesic potential. It can also refer to agents that minimize concomitant psychological disturbances such as insomnia, depression, or anxiety and drugs used to treat adverse effects of analgesics such as anti-emetics, laxatives, and psychotropics. ${ }^{27}$ Monoamine oxidase inhibitors (MAOIs) can cause severe reaction with opioids. The oneset can be very sudden and, with pathedine, can be fatal. ${ }^{33}$ The World Health Organization (WHO) has devised a "ladder" system to help structure initial and adjuvant analgesic medication choice (Table 1$) \cdot{ }^{34}$ Antacids containing magnesium salts should not be given as there may be magnesium retention. Antacids containing calcium or aluminium bases may impair absorption of penicillin $\mathrm{V}$ and sulphonamides. Cholestyramine, sometimes used in CRF, may also interfere with the absorption of penicillins. ${ }^{23}$ Patients with CKD often develop iron deficiency anaemia and require oral iron supplements or intravenous supplementation with iron dextrans, ferric gluconate, iron sucrose or ferumoxytol in addition to erythropoietin injections. ${ }^{35}$ Table 2 shows dose adjustment of some of the most used drugs in dentistry, depending on creatinine clearance. ${ }^{36}$

\begin{tabular}{|c|c|c|c|}
\hline Table 1. V & Tealth & $\mathbf{P}$ & \\
\hline $\begin{array}{l}\text { Step 1: Mild pain (rating } \\
\text { Non-narcotic analgesics ( } \\
\text { nonsteroidal anti-inflamm } \\
\pm \text { Adjuvant therapy }\end{array}$ & $\begin{array}{l}1-4 \text { on } 0-10 \text { scale) } \\
\text { acetylsalicylic acid, } \\
\text { ry drugs) }\end{array}$ & cetaminophen, & \\
\hline $\begin{array}{l}\text { Step 2: Mild to moderate } \\
\text { Opioids (eg. codeine, oxy } \\
\pm \text { Nonopioid } \\
\pm \text { Adjuvant therapy }\end{array}$ & $\begin{array}{l}\text { ain (rating of } 5-6 \text { on } C \\
\text { done, hydrocodone, }\end{array}$ & $\begin{array}{l}\text {-10 scale) } \\
\text { tramadol) }\end{array}$ & \\
\hline $\begin{array}{l}\text { Step 3: Moderate to sever } \\
\text { Opioids (eg. Morphine, hy } \\
\pm \text { Nonopioid } \\
\pm \text { Adjuvant therapy }\end{array}$ & $\begin{array}{l}\text { pain (rating of 7-100 } \\
\text { lromorphine, methadc }\end{array}$ & $\begin{array}{l}\text { o-10 scale) } \\
\text { one, fentanyl, oxycodine }\end{array}$ & \\
\hline $\begin{array}{l}\text { "Medications to counte } \\
\text { Anticonvulsants, antiepile }\end{array}$ & $\begin{array}{l}\text { ct opioid side effe } \\
\text { tics, corticosteroids, }\end{array}$ & $\begin{array}{l}\text { cts or provide additio } \\
\text { ind/or step } 1 \text { medication }\end{array}$ & $\begin{array}{l}\text { nal analgesia (eg } \\
\text { ). }\end{array}$ \\
\hline DRUGS & $\begin{array}{l}\text { DOSE ADJUSTMI } \\
\text { CLEARANCE }\end{array}$ & T ACCORDING TO & CREATINIINE \\
\hline & Normal dose & $\begin{array}{l}\text { Dose with CC 10-50 } \\
\text { ml/min }\end{array}$ & $\begin{array}{l}\text { Dose with CC } \\
<10 \mathrm{ml} / \mathrm{min} \\
\end{array}$ \\
\hline ANTIBIOTIC & & & \\
\hline Amoxicillin & $500 / 1000 \mathrm{mg} / 8 \mathrm{~h}$ & $500 / 1000 \mathrm{mg} / 8-12 \mathrm{~h}$ & $\begin{array}{l}500 / 1000 \mathrm{mg} / \\
12-24 \mathrm{~h} \\
\end{array}$ \\
\hline Amoxicillin/clavulanate & $500 / 875 \mathrm{mg} / 8 \mathrm{~h}$ & $\begin{array}{l}\text { No need for dose } \\
\text { adjustment }\end{array}$ & $\begin{array}{l}500 / 875 \mathrm{mg} / 12- \\
24 \mathrm{~h} \\
\end{array}$ \\
\hline Penicillin G & $\begin{array}{l}\text { 0'3-1'2 million IU/ } \\
\text { 6-12 h }\end{array}$ & $\begin{array}{l}50-100 \% \text { of the dose } \\
\text { every 8- } 12 \mathrm{~h}\end{array}$ & $\begin{array}{l}25-50 \% \text { of the } \\
\text { dose every } 12 \mathrm{~h}\end{array}$ \\
\hline Clindamycin & $300 \mathrm{mg} / 8 \mathrm{~h}$ & $\begin{array}{l}\text { No need for dose } \\
\text { adjustment }\end{array}$ & $\begin{array}{l}\text { No need for dose } \\
\text { adjustment }\end{array}$ \\
\hline Doxiciclin & $100 \mathrm{mg} / 24 \mathrm{~h}$ & $\begin{array}{l}\text { No need for dose } \\
\text { adjustment }\end{array}$ & $\begin{array}{l}\text { No need for dose } \\
\text { adjustment }\end{array}$ \\
\hline
\end{tabular}

\begin{tabular}{|c|c|c|c|}
\hline Erythromycin & $250-500 \mathrm{mg} / 6 \mathrm{~h}$ & $\begin{array}{l}\text { No need for dose } \\
\text { adjustment }\end{array}$ & $\begin{array}{l}\text { No need for dose } \\
\text { adjustment }\end{array}$ \\
\hline Metronidazole & $250-500 \mathrm{mg} / 6 \mathrm{~h}$ & Every 8-12 h & Every $12-14 \mathrm{~h}$ \\
\hline Azithromycin, & $\begin{array}{l}500 \mathrm{mg} / 24 \mathrm{~h}, 3 \\
\text { days }\end{array}$ & $\begin{array}{l}\text { No need for dose } \\
\text { adjustment }\end{array}$ & $\begin{array}{l}\text { No need for dose } \\
\text { adjustment }\end{array}$ \\
\hline \multicolumn{4}{|l|}{ ANTIFUNGAL } \\
\hline Anfotericin & 0 '3-1 mg/kg/24 h & $\begin{array}{l}\text { No need for dose } \\
\text { adjustment }\end{array}$ & $\begin{array}{l}0 \text { '3-1 mg/ kg/24- } \\
48 \mathrm{~h}\end{array}$ \\
\hline Fluconazol & $100-200 \mathrm{mg} / 24 \mathrm{~h}$ & $50-200$ every 24 h & $50-100$ every 24 h \\
\hline \multicolumn{4}{|l|}{ ANALGESIC } \\
\hline Paracetamol & $500-1000 \mathrm{mg} / 4-6 \mathrm{~h}$ & $\begin{array}{l}\text { No need for dose } \\
\text { adjustment }\end{array}$ & $\begin{array}{l}\text { No need for dose } \\
\text { adjustment }\end{array}$ \\
\hline Aspirin & \multicolumn{3}{|c|}{$\begin{array}{l}\text { Contraindicated (produces water retention, deterioration of } \\
\text { renal function and risk of gastric hemorrhage) }\end{array}$} \\
\hline Ibuprofen & $200-600 \mathrm{mg} / 4-6 \mathrm{~h}$ & $\begin{array}{l}\text { No need for dose } \\
\text { adjustment }\end{array}$ & $\begin{array}{l}\text { No need for dose } \\
\text { adjustment }\end{array}$ \\
\hline Dihidrocodeine & $10-30 \mathrm{mg} / 4-6 \mathrm{~h}$ & Decrease dose $25 \%$ & $\begin{array}{l}\text { Decrease dose } \\
25 \%\end{array}$ \\
\hline
\end{tabular}

\section{Renal nutrition management}

Diet counseling by a renal disease needs to be individualized based on many factors including: kidney function, lifestyle, culture, religion, financial status, other co-morbid conditions, treatment goals and biochemical parameters. The diet may have to be modified for sodium, protein, potassium and/or phosphorus. $^{37}$

Dietary protein: The benefits of dietary protein restriction for patients with chronic kidney disease (CKD) were established over 100 years ago. In 1869, Beale and colleagues showed that the uraemic symptoms in patients with kidney failure were ameliorated by reducing foods rich in protein. The benefits of dietary protein restriction are multifactorial. First, restricting protein in the diet provides favourable metabolic parameters. The typical biochemical profile (acidaemia, hyperphosphataemia, azotaemia) seen in CKD patients who receive minimal attention to their diet is not typically seen when proper dietary counseling is emphasised. Moreover, dietary protein restriction has been shown to improve insulin resistance and osteodystrophy. Patients with CKD (with an average GFR of $18 \mathrm{ml} / \mathrm{min}$ ) were given a protein-restrictive diet along with amino acid analogue supplements, and were found to maintain a neutral nitrogen balance without the development of acidaemia or hyperphosphataemia. ${ }^{38}$

Low-Phosphorus diet: The dietary phosphorus is mainly derived from 2 sources: dietary proteins and phosphorus additives. These additives are an important component of processed foods such as meats, cheeses, dressings, beverages, and bakery products. 
They can increase the dietary phosphorus intake by as much as $1 \mathrm{~g} /$ day. Nutrient composition tables usually do not include the phosphorus additives, which results in underestimation of phosphorus intake. Moreover, the phosphorus derived from plants is in the form of phytate and is less absorbable by the human intestines because of a lack of the enzyme phytase. In a study of 29,076 patients on haemodialysis, Shinaberger et al demonstrated that a high-protein/low-phosphorus diet is associated with the best survival, and the highest mortality rate was found in patients on low-protein/low-phosphorus diet. ${ }^{39}$

Phosphate binders: Phosphate binders are the mainstay of therapy for secondary hyperparathyroidism. The noncompliance to dietary restriction as well as the need to ensure adequate protein intake often result in the addition of phosphate binders to limit the net absorption of dietary phosphorus. In a recent study published in December 2008, patients treated with phosphate binders during the first 90 days after starting dialysis had a $30 \%$ lower risk of death compared with those who were not treated. Several modalities have been tried, including aluminum hydroxide, calcium salts, sevelamer hydrochloride (Renagel, Genzyme Corp., Cambridge, MA) and lanthanum carbonate (Fosrenol, Shire US, Inc., Wayne, PA). ${ }^{40}$

Vitamin D and its derivatives: Vitamin D is one of the oldest treatments for secondary hyperparathyroidism. It is known that calcitriol deficiency and resistance are major contributors to the pathophysiology of the disease and that calcitriol supplementation is effective in suppressing high levels of PTH. On the other hand, calcitriol enhances the intestinal absorption of calcium and phosphorus, increasing their blood levels and possibly increasing their product. ${ }^{41}$ The second-generation agents (Selective Vitamin D Analogues) cause less hypercalcemia and hyperphosphatemia than traditional calcitriol. Two agents are available and widely used in the United States: paricalcitol (Zemplar, Abbott Laboratories, Abbott Park, IL) and doxercalciferol (Hectorol, Genzyme Corp.). ${ }^{42}$

Sodium: The importance of salt restriction in the treatment of patients with renal disease has remained highly controversial. In patients with chronic kidney disease a high salt intake may be "nephrotoxic" by indirect mechanisms, e.g. by an increase in blood pressure and by attenuation of the pharmacologic blockade of the renin-angiotensin system blunting its anti-hypertensive and anti-proteinuric effect.
The sodium content of most commercially available food items is too high, and this accounts for nearly three-quarters of salt intake. There is strong evidence that salt intake plays an important role in the genesis of hypertension and target organ damage. Both high and low sodium intake cause adverse effects. The average salt intake of healthy children and adults exceeds, by far, the recommendations of current guidelines. ${ }^{43}$

\section{Conclusion}

The balance of blood chemistry is fundamentally affected by nutrition and the dietary intake of specific nutrients. The management of the renal patient, therefore, includes not only dose adjustment and restriction of drugs but dietary restriction and regulation as well, which may contribute to anxiety and aversion to further preventive instruction. In addition to good oral health promotion, there is an increased need for collaboration between the dental and medical professions to provide safe and appropriate dental care for these patients.

\section{References}

1.Johnson CA, Levey AS, Coresh $\mathbf{J}$ et al. Clinical practice guidelines for chronic kidney disease in adults: Part I. Am Fam Physician 2004;70:869-76.

2. Dirks J, Remuzzi G, Horton S, Schieppati A, Rizvi SAH. In: Jamison DT, Breman JG, Measham AR et al., editors. Diseases of the kidney and the urinary system. Disease control priorities in developing countries, 2nd ed. Washington (DC): World Bank; 2006.p.695-706.

3. Collins AJ, Foley RN, Chavers B et al. US renal data system 2011 annual data report: Atlas of end-stage renal disease in the United States. Am J Kidney Dis 2012;59:A7,el-420.

4. Ahmadieh A, Baharvand M, Fallah F, Djaladat H, Eslani M. Oral microflora in patients on hemodialysis and kidney transplant recipients. Iranian Journal of Kidney Diseases 2010;4:227-31.

5.World Kidney Day 2012. Bangladesh Renal Association, Bangladesh Cardiac Society, Kidney Foundation and Paediatric Nephrology Society of Bangladesh. [Discussion]. Available from: $\mathrm{http} / / /$ community.ejc.net/profiles/blogs/20-million-peo ple-are [accessed 19 November 2012].

6.Rashid HU. Renal data from Asia-Africa. Saudi J Kidney Dis Transplant 2004;15:185-89.

7. Patil S, Khandelwal S, Doni B, Rahman F, Kaswan S. Oral manifestations in chronic renal failure patients attending two hospitals in North Karnataka, India. OHDM 2012;11:100-6. 
8. Cohen EP. Chronic renal failure and dialysis. Nephrology: X. ACP Medicine, 2007.p.1-9. Available from: http://jewishhospital-cincinnati.com/files/ Chronic_Renal_Failure_and_Dialysis.pdf [accessed 27 November 2012]

9. Cawson RA, Odell EW. Renal disease. In: Parkinson M, Taylor A, Hewat C, editors. Essential of oral pathology and oral medicine, 8th ed. London: Elsevier Ltd; 2008.p.415-16.

10. Davidovich E, Schwarz Z, Davidovitch M, Eidelman E, Bimstein E. Oral findings and periodontal status in children, adolescents and young adults suffering from renal failure. $J$ Clin Period 2005;32:1076-82.

11. Akar H, Akar GC, Carrero JJ, Stenvinkel P, Lindholm B. Systemic consequences of poor oral health in chronic kidney disease patients. Clin J Am Soc Nephrol 2011;6:218-26.

12. Goldman M, Vanherwerghem JL. Bacterial infections in chronic haemodialysis patients: Epidemiologic and pathophysiologic aspects. Advan Nephrol Necker Hosp 1990;19:315-32.

13. Cervero AJ, Bagan JV, Soriano YJ, Roda RP. Dental management in renal failure: Patients on dialysis. Med Oral Patol Oral Cir Bucal 2008;13:419-26.

14. Epstein SR, Mandel I, Scoop IW. Salivary composition and calculus formation in patients undergoing haemodialysis. J Periodontol 1980;51:336-38.

15. Naugle K, Darby ML, Bauman DB et al. The oral health status of patients on renal dialysis. Ann Periodontol 1998;3:197-205.

16. Atassi F, Al-Shammery RA, Al-Ghamdi S. Gingival health among individuals on hemodialysis in Saudi population. Saudi Dental J 2001;13:82-86.

17. Chandra S, Chandra S, Chandra G, Kamala R. Renal diseases and oral medicine. In: Kohli A, Tikku AP, Editors. Oral Medicine, 1st ed. New Delhi: Jaypee Brothers Medical Publishers Ltd; 2007.p.170-73.

18. Dencheva M, Krasteva A, Gueorgieva Tzv, Kisselova A. Oral findings in patients with replaced renal function- a pilot study. Journal of IMAB 2010;16:54-57.

19. King GN, Healy CM, Glover MT et al. Prevalence and risk factors associated with leukoplakia, hairy leukoplakia, erythematous candidiasis, and gingival hyperplasia in renal transplant recipients. Oral Surg Oral Med Oral Pathol 1994;78:718-26.
20. Mozaffari PM, Amirchaghmaghi M, Mortazavi H. Oral manifestations of renal patients before and after transplantation: A review of literature. DJH 2009;1:1-6.

21. Imirzalioglu P, Onay EO, Agca E, Ogus E. Dental erosion in chronic renal failure. Clin Oral Investig 2007;11:175-80.

22. Naylor GD, Hall EH et al. The patient with chronic renal failure who is undergoing dialysis or renal transplantation: another consideration for antimicrobial prophylaxis. Oral surg Oral Med oral Pathol 1988;65:116-21.

23. Scully C, Cawson RA. Genitourinary and renal disease. In: Parkinson M, editor. Medical problems in dentistry, 5th ed. New Delhi: Elsevier Ltd; 2005.p.115-22.

24. Brockmann W, Badr M. Chronic kidney disease: Pharmacological considerations for the dentist. J Am Dent Assoc 2010;141:1330-39.

25. Al-Wakeel JS, Mitwalli AH, Huraib S et al. Serum ionic fluoride levels in haemodialysis and continuous ambulatory peritoneal dialysis patients. Nephrol Dial Transplant 1997;12:1420-24.

26. Petifor JM, Schnitzler CM, Ross FP, Moodley GP. Endemic skeletal fluorosis in children: hypocalcemia and the presence of renal resisitance to parathyroid hormones. Bone Miner 1989;7:275-88.

27. Sulejmanagic H, Sulejmanagic N, Prohic S, Secic S, Meseljic S. Dental treatment of patients with kidney diseases. Bosnian Journal of Basis Medical Sciences 2005;5:52-56.

28. Glick N, Davison SN. Managing chronic pain in advanced chronic kidney disease. US Nephrology 2011;6:21-28.

29. Editor's Choice: An update on analgesics. Br. J. Anaesth 2011;107:19-24.

30. Rang ST, West NL, Howard J, Cousins J. Anaesthesia for chronic renal disease and renal transplantation. EAU-EBU 2006;4:246-56.

31. Stewart P, Harris D. Update in anaesthesia: Chronic renal failure and anaesthesia. World Federation of Societies of Anesthesiologists; 2000.p.7-10.

32. Gandhi BV, Bahadur MM, Dodeja $\mathrm{H}$ et al. Systemic fungal infections in renal diseases. J Postgrad Med 2005;51:S30-S36.

33. Cawson RA, Odell EW. Emergencies in dental practice. In: Parkinson M, Taylor A, Hewat C, editors. Essential of oral pathology and oral medicine, 8 th ed. London: Elsevier Ltd; 2008.p.448-53. 
34. Rifkin BS, Perazella MA. Analgesic therapy in patients with chronic kidney disease: A case-based approach. Hospital Physician 2005;43:13-22.

35. Rozen-Zvi B, Gafter-Gvili A, Paul $M$ et al. Intravenous versus oral iron supplementation for the treatment of anaemia in CKD: systematic review and meta-analysis. Am J Kidney Dis 2008;52:897-906.

36. Martí Álamo S, Gavaldá Esteve C, Sarrión Pérez MG. Dental considerations for the patient with renal disease. J Clin Exp Dent 2011;3:112-19.

37. Diet for diabetes and chronic kidney disease: Tips for health professionals. Diet for Diabetes and CKD; 2009.p.1-10. Available from: http://www.diabetes.ca/ files/for-professionals/diet-kidney-disease [accessed 19 November 2012].

38. Khosla UM, Mitch WE. Dietary protein restriction in the management of chronic kidney disease. US Nephrology 2008;3:32-36.
39. Saliba W, El-Haddad B. Secondary hyperparathyroidism: Pathophysiology and treatment. J Am Board Fam Med 2009;22:574-81.

40. Isakova $\mathrm{T}$, Gutiérrez $\mathrm{OM}$, Chang $\mathrm{Y}$ et al. Phosphorus binders and survival on hemodialysis. $\mathrm{J}$ Am Soc Nephrol 2009; 20:388-96.

41. Palmer SC, McGregor DO, Macaskill $P$ et al. Meta-analysis: vitamin D compounds in chronic kidney disease. Ann Intern Med 2007;147:840-53.

42. Teng M, Wolf M, Lowrie E et al. Survival of patients undergoing haemodialysis with paricalcitol or calcitriol therapy. N Engl J Med 2003;349:446-56.

43. Ritz E, Mehls O. Salt restriction in kidney disease-a missed therapeutic opportunity. Pediatr Nephrol. 2009;24: 9-17. 